\section{Commentary: Are we confident in abandoning $P$ values, or is this just the interval?}

\author{
Vaibhav Gupta, MD, ${ }^{\mathrm{a}}$ and \\ Biniam Kidane, MD, MSc, FRCSC ${ }^{\mathrm{b}, \mathrm{c}, \mathrm{d}}$
}

In the April 2021 issue of The Journal of Thoracic and Cardiovascular Surgery, we were refreshed to read the expert statistical opinion by Dr Paul Visintainer, ${ }^{1}$ suggesting a move away from static $P$ values to more informative confidence intervals, with the ultimate aim of enhancing our interpretation and application of clinical research.

In performing statistical testing, we obtain 3 outputs: (1) the point estimate, which measures the size and direction of effect of an exposure on outcome compared with a control; (2) the confidence interval, which indicates the range within which the true value might lie, if the study were repeated; and (3) the $P$ value, which is a widely used, but often misunderstood and misused, entity. Assuming that the null hypothesis is true (ie, no difference between intervention and control), the $P$ value will answer the question: "What is the chance that we will get data/results as extreme (or more extreme) as those seen in this experiment?" As most people already know, the threshold by which we judge that the null hypothesis can be rejected has been arbitrarily set at a value of $P<.05$, as a matter of convention.

Visintainer ${ }^{1}$ articulates a coherent and comprehensible rationale for placing increasing emphasis on confidence intervals rather than $P$ values. This recommendation is in line with position statements from leading medical journals and statistical societies released in recent years. ${ }^{2-4}$ We hope his

\footnotetext{
From the ${ }^{\mathrm{a}}$ University of Toronto, Toronto, Ontario, Canada; ${ }^{\mathrm{b}}$ Section of Thoracic Surgery, Department of Surgery, Rady Faculty of Health Sciences, and ${ }^{\mathrm{c}}$ Department of Community Health Sciences, University of Manitoba, Winnipeg, Canada; and ${ }^{\mathrm{d}} \mathrm{Re}-$ search Institute in Oncology and Hematology, Cancer Care Manitoba, Winnipeg, Canada.

Disclosures: The authors reported no conflicts of interest.

The Journal policy requires editors and reviewers to disclose conflicts of interest and to decline handling or reviewing manuscripts for which they may have a conflict of interest. The editors and reviewers of this article have no conflicts of interest.

Received for publication March 30, 2020; revisions received March 30, 2020; accepted for publication March 31, 2020; available ahead of print April 12, 2020.

Address for reprints: Biniam Kidane, MD, MSc, FRCSC, Health Sciences Centre, GE-611, 820 Sherbrook St, Winnipeg, Manitoba R3A 1R9, Canada (E-mail: bkidane@hsc.mb.ca).

J Thorac Cardiovasc Surg 2022;164:e41-2

$0022-5223 / \$ 36.00$

Copyright (c) 2020 by The American Association for Thoracic Surgery

https://doi.org/10.1016/j.jtcvs.2020.03.131
}

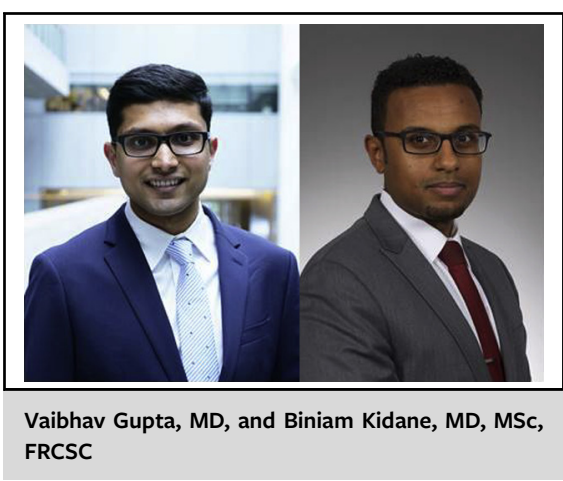

CENTRAL MESSAGE

Effect estimates and confidence intervals are more informative and relevant to clinical decisionmaking than static $P$ values and should be favored in cardiothoracic research.

expert opinion piece will help educate our readers and motivate our authors to follow his recommendations.

One important point to reinforce is that "nonsignificant" $P$ values do not prove that differences do not exist between the compared groups. The correct statistical interpretation of a nonsignificant $P$ value is that the study did not have sufficient evidence to reject the null hypothesis of no difference between $A$ and $B$. This does not mean that a difference does not exist between $\mathrm{A}$ and $\mathrm{B}$, nor that $\mathrm{A}$ and $\mathrm{B}$ are equivalent; it simply means the study was not able to detect a difference. This is a foundational concept in clinical statistics that continues to be misquoted from clinical care to clinical congresses and then disseminated to, and consumed by, the general public.

In addition to confidence intervals, whose utility is welldescribed by Visintainer, ${ }^{1}$ we can increasingly use Bayesian analyses in surgical research. Such an undertaking has been simplified with the advancement in the processing power of our off-the-shelf computers and the availability of statistical software to run these analyses. In Bayesian analysis, prior beliefs and understanding of a clinical problem can be explicitly modeled and considered when studying the association between exposure and outcome. It is important to note that "prior beliefs" are not just personal opinions; rather, these prior beliefs represent the state of evidence regarding that issue up until the time when the experiment is undertaken. Thus, we can test our hypothesis, taking our prior beliefs, or many different prior beliefs, into consideration. The 
results will show whether our prior beliefs are in concordance with what the data show or whether the data are strong enough in the other direction to overwhelm our prior beliefs. It is, philosophically, moving more toward thinking about whether a result fits with our clinical thinking and helps incorporate clinical thinking into the analysis.

One final point pertains to the concerns among researchers and clinicians alike that wholesale abandonment of $P$ values will result in a chaotic situation wherein the end users of evidence are left not knowing who or what to trust, akin to a lawless frontier town where the sheriffs have abandoned their post. $^{4,5}$ This concern can be mitigated by, instead, focusing on the effect estimate and its uncertainty, an output that is obtained in conjunction with the $P$ value but often not reported. In fact, effect estimates are more directly related to clinical decision-making, ${ }^{4}$ as they help us understand what degree of effect an intervention will have on our patient and what the expected range of response is. ${ }^{5}$ This suggestion is precisely in line with the suggestion by Visintainer $^{1}$ to adopt confidence intervals and does not require more sophisticated statistical understanding or analysis.
As statistical understanding has advanced, and statistical education has been increasingly incorporated into surgical training in academic programs, we have the opportunity to adopt more appropriate methodologic techniques to answer our clinical questions, communicate the answers we find, and, ultimately, bring improvements to patient care. As surgeons, we are experienced in innovating and adopting new technologies, and, similarly, we must be prepared to move beyond our historical reliance on $P$ values to more nuanced analyses of surgical data.

\section{References}

1. Visintainer P. Moving beyond significance testing: confidence intervals in clinical research. J Thorac Cardiovasc Surg. 2021;161:1373-6.

2. Harrington D, D'Agostino RB Sr, Gatsonis C, Hogan JW, Hunter DJ, Normand ST, et al. New guidelines for statistical reporting in the journal. N Engl J Med. 2019; 381:285-6.

3. Wasserstein RL, Lazar NA. The ASA statement on p-values: context, process, and purpose. Am Stat. 2016;70:129-33.

4. Wasserstein RL, Schirm AL, Lazar NA. Moving to a world beyond "p $<0.05$ ". Am Stat. 2019;73(suppl 1):1-19.

5. Ioannidis JPA. The proposal to lower P value thresholds to .005. JAMA. 2018;319: 1429-30.
Commentary: Can I trust the $P$ value?

\author{
Aaron J. Weiss, MD, ${ }^{a}$ and \\ Anelechi C. Anyanwu, MD, FRCS ${ }^{b}$
}

It has been 15 years since physician-scientist and "scourge of sloppy science" ${ }^{\text {D }}$ Dohn Ioannidis published his seminal paper titled "Why Most Published Research Findings are False." In it, he proclaims that, "Several methodologists have pointed out that the high rate of nonreplication (lack

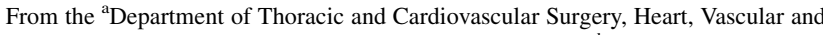
Thoracic Institute, Cleveland Clinic, Cleveland, Ohio; and ${ }^{\mathrm{b}}$ Department of Cardiovascular Surgery, Mount Sinai Medical Center, New York, NY.

Disclosures: The authors reported no conflicts of interest.

The Journal policy requires editors and reviewers to disclose conflicts of interest and to decline handling or reviewing manuscripts for which they may have a conflict of interest. The editors and reviewers of this article have no conflicts of interest.

Received for publication April 25, 2020; revisions received April 25, 2020; accepted for publication April 26, 2020; available ahead of print May 11, 2020.

Address for reprints: Aaron J. Weiss, MD, Department of Thoracic and Cardiovascular Surgery Heart, Vascular, and Thoracic Institute, Cleveland Clinic, 9500 Euclid Ave, Desk J4-1, Cleveland, OH 44915 (E-mail: weissa2@ccf.org).

J Thorac Cardiovasc Surg 2022;164:e42-4

$0022-5223 / \$ 36.00$

Copyright (c) 2020 by The American Association for Thoracic Surgery

https://doi.org/10.1016/j.jtcvs.2020.04.125
}

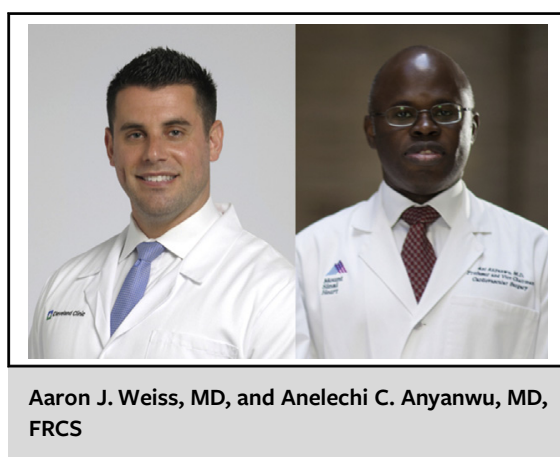

CENTRAL MESSAGE

Our proposed checklist, "can I trust the P value?," can be used as a roadmap for individual readers to critically evaluate the appropriateness of published $P$ values. 